\title{
Ryan E. Carlin, Matthew M. Singer, and Elizabeth J. Zechmeister (eds.) (2015). The Latin American Voter: Pursuing Representation and Accountability in Challenging Contexts. Ann Arbor: University of Michigan Press, 429 pp.
}

\author{
FEDERICA SÁNCHEZ STANIAK
}

Pontificia Universidad Católica de Chile

The Latin American Voter, edited by Carlin, Singer and Zechmeister, is a much welcomed addition to the study of politics in the region, especially contributing to the literature on comparative electoral behavior which is relatively scarce but altogether growing across different areas within the field. The book is a compilation of essays by top scholars divided into four parts analyzing the characteristics of the average Latin American voter not only in terms of gender, ethnicity and religion but also explaining the way electors respond to clientelism, partisanship and the influence of left-right identifications. The final part discusses the different ways in which the voters hold their leaders accountable based on their perception of government performance in areas such as corruption, crime and economic achievement. Overall, this volume is quite significant regarding the amount of information and perspectives used to define, describe and evaluate Latin Americans as regular voters.

The Latin American Voter makes extensive use of the Americas Barometer database based on the Latin American Public Opinion survey hosted by Vanderbilt University and compiled every other year since 2004. This rich individual level time series cross sectional data allows the researchers to develop many different hypotheses and compare individual voters' behavior across countries in the region while at the same time contrasting the results with what has been proposed about electoral behavior worldwide.

One of the guiding questions that crosscuts through the individual chapters is whether most of the tried and true explanations for electoral behavior in advanced democracies can be applied to the voters in this part of the world. Are the Latin American voters similar to the American or European ones? Do the same variables influence vote choice across the board? Are voters concerned by the same things? Do they react to the same stimuli in an analogous manner?

In part, one of the main conclusions is that voters in Latin America are indeed very similar to voters elsewhere in spite of the traditional stereotype of countries marred by clientelism and corruption. Yet, the most interesting finding is that there is no single Latin American voter. Beyond the similarities there is still very important intra regional variation with countries showing quite distinct patterns of behavior. In fact, the compilation of essays seems to paint a picture not only of many voters but also of many Latin Americas as well. The data and results from the research supporting this book suggests patterns that point towards clusters of countries which trend together: Central America on one hand, the Andean Region on 
another and still different from these two, the Southern Cone. Notwithstanding, there are countries like Brazil, Colombia and Bolivia that seem to march to their own tune, sometime falling within regional trends and at times showing more unique types of behavior.

Part I introduces the reader to the Latin American voter through a compact analysis of the most important socioeconomic, psychological and institutional variables known to affect voter turnout in the rest of the world. As is the case in other democracies, education, income, employment, partisanship and interest in politics among other covariates are positively related to turnout. Moreover, they find that at the contextual level compulsory voting with tightly enforced sanctions and slightly higher degrees of party system polarization even out the differences in participation between different social groups. In other words, the first part proposes and tests the traditional alternative theories of turnout using individual and contextual level variables now available for the region.

The second part focuses the attention on demographics and its impact on the vote. Boas and Smith's chapter on religion finds that while the religious-secular cleavage is indeed expressed through ideological voting with secular individuals voting on the left and believers on the right, the interreligious differences (between Catholics and Protestants) are not picked up this way. Nonetheless, there is considerable ingroup bias and outgroup reject when identity voting is activated; protestants prefer voting for one of their own before supporting a Catholic or a secular candidate for office. Regarding gender and the advancement of women in politics, Morgan finds that a traditional gender gap (women voting on the right) still dominates Latin American politics while women empowerment seems to reduce it. An interesting finding is that motherhood makes women more conservative. However, this begs the questions of whether motherhood could be picking up the effect of a decrease in autonomy after childbirth? It can also be argued that the loss of autonomy is quite difficult to measure and may only be considering part of the concept with the variables available here (employment, marital status and gender inequality in household income). On another subject, Moreno finds that when ethnicity is salient and the cleavage is politicized, the probability that this variable will influence preferences is enhanced. Although Mexico, Peru and Guatemala have considerably large indigenous populations, the success of ethnic politics has not blossomed in these countries as it has in Bolivia with Evo Morales' MAS. The most significant explanation the author finds to account for regional variation is related to the availability and emergence of individual leaderships able to profit from opportune moments for ethnic mobilization. A similar argument is proposed by Mainwaring, Torcal and Somma in their study of class voting. In addition to the fact that the intensity of class voting shows large intra-regional differences and that it seems to be stronger among the poorer self-employed part of the population, they conclude that class voting as such needs to be activated. They relate it to the left turn of the early 2000s when leftist parties came to power campaigning on typical class cleavage platforms like income redistribution and social justice.

Part III reflects on how the voters make up their minds in response to what the parties offer in terms of policies, ideology, identification and material goods. Baker and Greene find that there is some positional voting based on personal economic policy preferences. They suggest Latin America might be currently in the process of developing more programmatic party systems in line with the expectations of modern democratic representation, transcending 
the charismatic, populist and clientelistic elite-mass linkages that predominate in the region. The panel data studies on Brazil and Mexico provide an interesting approach but are hard to replicate elsewhere without the appropriate data. Zechmeister's research analyzes the extent to which Latin Americans' vote choices reflect their left-right identifications in terms of policy positions. Her findings point towards a great intraregional diversity. Her study is quite interesting because it explores different domains of the LR placements and its relation to issue preferences and vote choice. While it may not guide it for most countries, it is on average connected to vote choice across the region with a stronger effect in Chile, El Salvador and Paraguay and a weaker one in Panama, Costa Rica and Argentina. The differences are based on the level of polarization, the effective number of parties, the degrees of programmaticness of the party system and clientelism. Lupu analyzes the state of partisanship in the region and finds that unlike what most people think this is not based on clientelism, albeit certain exceptions. In Latin America, although mass partisanship has suffered a considerable decline, existing partisans are similar to their peers in more advanced democracies in the sense that they are generally more informed, attentive and engaged, participating in politics at higher levels than non-partisans and allowing their party attachments to influence their vote choice. This section is closed by Kitschelt and Altamirano's study on the effectiveness of clientelistic practices in Latin America. Their findings suggest that efforts do not pay off as expected even if clientelism is still relevant as a party strategy across the region. Against all odds, the rise of left populist parties has the strongest negative effect on clientelistic effectiveness.

The last part of the book reviews the extent to which voters hold their leaders responsible for performance success or failure in domains such as crime, corruption and economics. All three analyses start out from the premise that incumbents that run for reelection are likely to be rewarded for good performance but punished with votes for opposition parties or abstention when they fail to meet the expectations of the electorate during their time in office. This will only be possible when voters can accurately attribute responsibility for policy outcomes and when they have alternative choices to vote for. Gélineau and Singer's study of economic voting in Latin America concludes that voters in the region consider both the economic and political context when they assign blame for economic outcomes. They argue the talent of the party system to frame the choice in terms of who's to blame for the economy is significant for the existence of economic voting. When outcomes can be blamed on international economic trends or globalization, the economic vote is reduced but when the incumbent is clearly understood to have political control over economic policy and measures, then the effect of economic voting becomes stronger. In their chapter on the effects of corruption on vote choice, Manzetti and Rosas find that in countries where corruption is perceived to be more extensive, those with a higher perception of the problem are more likely to cast a vote against the incumbent. Furthermore, they establish a relationship between corruption perception and economic performance concluding that the corrupt incumbents who do not tackle inflation but instead focus on employment and growth are more likely to be punished by the electorate. Like in the case of economic voting, clarity of responsibility and the effect of globalization matter as well. Finally, Pérez focuses on crime and proves that perception of insecurity is a stronger and more consistent predictor of voting for the opposition than crime victimization. It comes as no surprise that in the most violent region 
of the world, where violent crime rates reign the highest, the government's attitudes, efforts and performance in this area are carefully scrutinized and taken into account when deciding whether to vote for the incumbent or supporting another alternative candidate.

To be fair, it must be acknowledged that The Latin American Voter surveys a great range of topics in electoral behavior making an important contribution to the understanding of the way voters choose their representatives in the region. Nevertheless, there is a part of the story that this book leaves untold which has to do with the crisis of representation, the dramatic decrease in turnout levels across countries, increased volatility, disenfranchisement and apathy among the Latin American non-voters. The full picture of who we are as individuals with political rights needs to incorporate this negative side of electoral behavior as well. In Colombia for example, given the dwindling turnout rates the legislators even considered the potential introduction of compulsory voting. Costa Rica has experienced a steady decrease in turnout since 1994 from $81 \%$ to $55 \%$ in the last presidential elections. Yet, nowhere has this problem been more evident than in Chile where even after an electoral reform to make registration easier as a way to motivate turnout, abstention rates spiked at $60 \%$ in 2012. It appears to be a contradiction that some of the most institutionalized and stable democracies in Latin America are currently experiencing such a phenomenon of distancing from politics. As Lijphart (1997) explains, turnout is important because it has a direct influence on representation and unequal participation is associated with an unequal influence on politics and government which becomes systematically biased in favor of the most privileged sectors who enjoy higher levels of education and income.

In conclusion, The Latin American Voter makes a remarkable contribution to the literature on the study of voting, representation and comparative electoral behavior considering the many variables that influence vote choice in the region. It shows the theories and explanations travel well when tested outside the context of the United States and other advanced democracies. On the one hand, it seems possible to make an argument for a universal voter who is more or less influenced in the same way across different settings. However, on the other, the book succeeds in explaining how it is inappropriate to talk about a single voter profile given the fact that a great diversity is found in the many different countries within Latin America. Further research should work towards deepening our knowledge of political behavior in this part of the world, while keeping in mind the comparative value of our many cultural, social, attitudinal and political differences.

\section{REFERENCE}

Lijphart, Arend. 1997. “Unequal Participation: Democracy's Unresolved Dilemma”. American Political Science Review 91 (1): 1-14.

Federica Sánchez Staniak is BA in International Relations from Universidad del Salvador, Argentina, MA in Political Science from University of Houston, USA and PhD candidate from Pontificia Universidad Católica de Chile. E-mail: fedestaniak@gmail.com. 